\title{
Nuevas observaciones sobre el uso de la Fenil-Butazona en las obstrucciones tubarias
}

\author{
Dr. Jorge Amorocho Carreño
}

En el estudio de la esterilidad matrimonial es frecuente encontrar como una de sus causas la impermeabilidad tubaria, de etiología conocida o no. La solución de tal problema ha sido preocupación de todos los ginecólogos que han buscado un tratamiento que permita la recuperación funcional de las trompas. Han sido varias las terapéuticas ideadas con tal fin, pero puede decirse que el problema aún subsiste, ya que ninguna de ellas ha dado los resultados esperados en forma consistente.

Anteriormente se empleó la fisioterapia como el principal de los recursos para tratar de restablecer la permeabilidad de los conductos una vez que se lograba el enfriamiento de las afecciones inflamatorias salpingeas; esta fisioterapia variaba desde las duchas calientes, baños de asiento y calor abdominal, hasta sistemas más modernos, como las ondas cortas y ultra cortas. Los resultados obtenidos fueron variables, pero generalmente pobres, pues las lesiones remanentes del ataque inflamatorio agudo no lograban hacerse desaparecer con estos métodos, que por lo demás adolecen del defecto de tener que ser aplicados durante un tiempo bastante largo.

Con el advenimiento de los quimioterapéuticos y antibióticos, mejoró sensiblemente el pronóstico de las oclusiones tubarias consecutivas a infecciones venéreas o puerperales, al hacer más corto el período activo de la infección, logrando en muchos casos hacer abortar la enfermedad. Sinembargo, es de cuotidiana observaciónó el caso de pacientes que posiblemente fueron insuficientemente tratadas o que sufrieron inflamaciones que pasaron inadvertidas o no fueron debidamente diagnosticadas en su ocurrencia: aquella paciente que no presenta historia alguna de infección genital, en ocasiones relar 
tivamente recién casada, y que sinembargo, en el curso de un estudio de esterilidad presenta oclusión de las trompas, comprobada por los diferentes métodos que se emplean en tales casos.

Estas pacientes, lógicamente, han escapado a la terapéutica antibiótica que hubiera podido prevenir la lesión obstructiva.

Recientemente, se han empleado, con $\mathrm{cl}$ fin de provocar el ablandamiento o disolución del material fibroso o fibrinoso que constituye la secuela de la inflamación activa y que es el causante de la oclusión tubaria, corticoides del grupo glucocorticoide, que tienen acción antiflogistica y resolutiva, al lado de su acción metabólica.

Las principales experiencias se han llevado a cabo con corti.. sona, y las pocas de mi práctica particular, con prednisona. Los resultados de la terapéutica oral han sido bastante pobres. El empleo de los corticoides, aparte de no dar los resultados esperados, tien el inconveniente de producir efectos secundarios y de ser intolerados en muchos casos, no dejando de prcocupar al médico tratante la posibilidad de una inhibición secundaria de las glándulas suprarenales.

El sistema relativamente nuevo, de hidrotubaciones empleando antibióticos de amplio espectro, solos o combinados con corticoides o enzimas, tampoco presenta resultados muy halagueños.

Tuvimos ocasión de hacer un estudio sobre el empleo de la fenilbutazona en el tratamiento de las inflamaciones pélvicas en sus fases aguda y sub-aguda, encontrando resultados muy satisfactorios.

Trabajo preliminar sobre este tema fue presentado por nosotros en la Segunda Convención Nacional de Ginecología y Obstetricia reunida en Cali en 1955.

Sabiendo que la fenil-butazona tiene como principales efectos los de ser analgésica, antitérmica, antiflogística, fibrinolítica y modificadora de la permeabilidad capilar, efectos todos ellos compr $\therefore$ b?dos experimental y clínicamente en multitud de trabajos, hemos querido aprovechar especialmente las tres últimas cualidades de la droga, con el fin de tratar de lograr el restablecimiento de la permeabilidad tubaria, en aquellos casos en los cuales se encontraba obstrucción sin proceso infeccioso activo.

Aunque el número de casos presentados es muy escaso, hemos querido exponerlos con el objeto de estimular más el uso experimental de este tratamiento, para poder, en un futuro, reunir suficientes conceptos scbre su bondad. 


\section{MATERIAL Y METODO}

Se tomó un grupo de pacientes que consultaron por esterilidad matrimonial primaria o secundaria, y en las cuales se eliminó previamente la presencia de cualquiera de los otros factores (marido, ovárico, cervical, etc.), que pudieran ser la causa de ella, es decir, que se tomó como punto de partida experimental la existencia de impermeabilidad tubaria.

El criterio básico para juzgar la existencia de ella fue el siguiente:

De catorce pacientes estudiadas, dos tenian pruebas de Rubin negativas e histerosalpingografías que demostraban impermeabilidad tubaria.

De las otras doce, se juzgaron trompas impermeable; aquellas de pacientes que fucron sometidas a dos o más pruebas de Rubin con resultados negativos. Después de una primera prueba negativa, se hizo una segunda, dentro de un lapso de una semana, sometiendo a la paciente a un tratamiento previo de tres días con antiespasmódicos, bien fuera derivados de la atropina. (Atrinal) bien de la hioscina (Buscapina). Tanto la primera como la segunda prueba se con sideraron negativas cuando el manómetro demostró una presión de gas mínima de $18 \mathrm{cms}$. durante un tiempo mínimo de tres minutos.

Dentro de la misma prueba se hizo alcanzar al gas esta presión por lo menos dos veces. Cuando se llegó a la conclusión de que existía una oclusión tubaria, se sometió a las pacientes a tratamiento. En ninguno de los casos existían antecedentes de infección específica (gonococo, etc.).

De catorce pacientes con diagnóstico de oclusión tres fueron tratadas con corticoides y doce con fenilbutazona. El tratamiento con corticoides consistió en la administración diaria de 15 mlgs. de prednisona, durante un lapso de dos semanas. De las tr $\mathrm{s}$ pacientes estudiadas, dos manifestaron intolerancia a corto plazo y una alcanzó el tiempo fijado; de las once tratadas con fenil-butazona, nueve recibieron una primera serie de seis inyecciones de la droga y dos recibieron dos series consecutivas con dos días de intérvalo y seis inyecciones por serie.

Una vez terminado el tratamiento, se sometió a las pacientes a nuevas persuflacciones, nunca más de dos. Se siguió como criterio de resultado positivo el paso del gas a presión no mayor de $18 \mathrm{cms}$. y que al ser repetida la persuflación, el gas pasara a la cavidad peritoneal a presión no superior de $9 \mathrm{cms}$. 


\section{RESULTADOS}

I-La paciente que pudo seguir el curso completo de tratamiento con prednisona, demostró en una nueva prueba de Rubin efectuada en las mismas condiciones que las anteriores, impermeabilidad tubaria.

II - De las once pacientes tratadas con fenil-butazona, nueve demostraron una prueba de Rubin positiva.

III-Entre estas nueve pacientes, se encontraban las dos que tuvieron histerosalpingografía previa.

IV - Entre las nueve pacientes se encontraron las dos que siguieron dos series de inyecciones de fenilbutazona.

$\mathrm{V}-\mathrm{De}$ las nueve pacientes con resultados positivos, siete concibieron en el curso de dos a seis meses.

\section{RESUMEN Y CONCLUSIONES}

Se presenta una corta serie de casos de esterilidad primaria, cuya causa se diagnosticó como impermeabilidad tubaria. De los casos presentados no se obtuvieron buenos resultados en los tratados con corticoides.

La simplicidad y los resultados obtenidos con el tratamiento con fenilbutazona son francamente halagueños. Dado que se trata de una serie muy corta, y que por lo tanto debe considerarse como comunicación preliminar, no es posible sacar conclusiones al respecto, pero su presentación tiene como objeto el solicitar e incitar a un mayor estudio en el uso del fármaco en los casos indicados.

\section{BIBLIOGRAFIA}

1- GAUDIN, KUSSELl. Med. Panamericana. Vol III N² 1954.

2- DAMENJOZ. International Record of Med. Vol. $165 \mathrm{~N}^{\circ} 91952$.

3- R. LUYOT. La Phenyl-Butazone ey Therapeutique - Hospital de Nancy- 1954.

4- BUCHER O. The effect of Butazon. on connective tissue. Schweiz, med. maforsch. 14-22 (1955).

5- SCHUMACHER $H$. Experimental investigation into the mech. of the antinflamatory action of butazolidin, cortisone and salicilic acid. Zschr. Reu6- I. STEIN-ALAN ROSE. Treatement of superficial trombophlebitis with F.B.

7- WAGNER, H. Tratamiento analgésico, antiflogístico y resolutivo de los 
procesos inflamatorios de los anexos. A. erztl. Wschr. 6-832 (1951).

8- A. MASSANO Y YACCARONE. L'irgap.rina e la Butazolidina nella terapia analg. ed antiflog. dei processi inflamatori annessiali. Minerva Ginecológica-17 (1954).

9- RUBIRALTA. Empleo de Irgapirina como analgésico y antiflogístico en las afecciones ginecológicas. Rev. Cir. Hospital Juárez 1-7 (1954).

10- SCHMIDT H. -STEINMANN- Empleo de la irgapirina en Ginecología. Zem. Blatt. f. Gyn. 75-48 (1953).

11- CARRERAS ROCA. Clasilicacón y tratamiento de las algias anexiales. XI Congreso de Ginecoología y Obstetricia. Mayo 1952.

12- AMOROCHO CARREÑO JORGE. Tratamiento de las afecciones enexo parametriales con fenil-butazona. Memorias de la Segunda Convención Colombiana de Obstetricia y Ginecología. 315-321 (1955).

13 - AMAYA LEON HERNANDO. Cortisona en el tratamiento de la Obstrucción tubaria. Rev. Col. Obst. Gin. $N^{\circ} 6$ Nov. Dic. 1958.

14- KURZROK L. STREIM. Cortogen Treatement fo: Sterlity due to nonpatent tubes. Fertility and S'er li:y 1954 